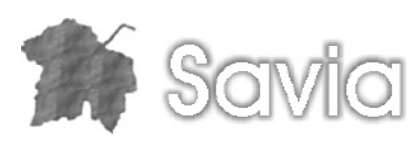

Investigación

\title{
Las políticas públicas frente a la diversidad socioespacial y simbólica
}

\author{
Manuela Guillén Lúgigo*
}

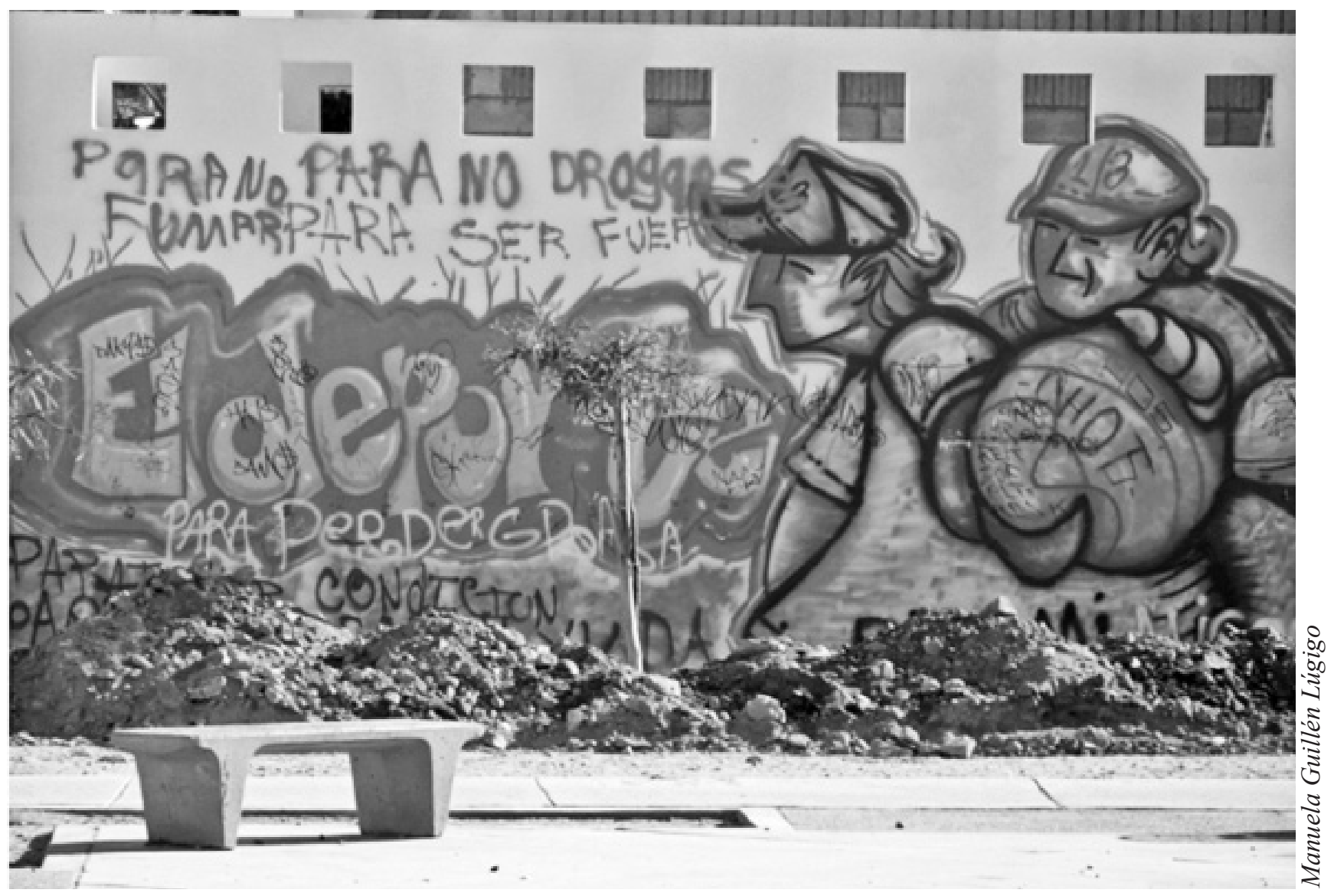

\section{Resumen}

El presente trabajo tiene el propósito de reflexionar sobre la diversidad y heterogeneidad simbólica de los contextos de segregación urbana, a los cuales están dirigidos gran parte de los programas de combate a la pobreza. En particular nos interesa reflexionar en torno a algunas de las implicaciones prácticas y simbólicas de dicha diversidad, encontradas en dos barrios de la periferia de Hermosillo. Dichos barrios constituyeron el escenario de una investigación realizada con el propósito de identificar las representaciones sociales que se construyen en escenarios de segregación urbana.

\begin{abstract}
The purpose of this paper is to reflect about the diversity and symbolic heterogeneity in urban segregated contexts, to which most of the programs to alleviate poverty are aimed. Specially, we are interested in reflecting about some practice and symbolic implications of such diversity that were found in two neighborhoods of the periphery of Hermosillo. The mentioned neighborhoods were the scenery of a research, which purpose was to identify the social representations built in urban segregated spaces.
\end{abstract}

Departamento de Trabajo Social. Universidad de Sonora.mguillen@sociales.uson.mx 


\section{Introducción}

La inserción de México en el mercado global ha implicado no solamente una relación comercial desigual, también ha generado cambios socioculturales importantes en distintas esferas. En el caso de México se han producido reconfiguraciones económicas que han traído de la mano nuevas formas de trabajo, implicadas en procesos socioculturales complejos, en los que lo tradicional y lo moderno, lo global y lo local, adquieren una específica concreción histórica.

En este aspecto de la globalización cohabitan el azadón con el microchip, las formas indígenas de organización y representación simbólica del trabajo con pautas laborales estandarizadas globalmente por compañías transnacionales. Los contrastes geográficos tan sorprendentes en la geografía mexicana no son menores en su geografía humana y en su tejido social.

A decir de Roberto Zallo (2000), el paradigma de la globalización es insuficiente para explicar los cambios sociales en curso porque - entre otros factores - la configuración de tendencias específicas, como la diversidad cultural y las economías regionales, suponen contratendencias relativamente compensatorias de la globalización. Con esto se refiere que muchos de los cambios sociales y económicos, que tienen lugar en los territorios, no se derivan de la mundialización sino a pesar de ella. Lo anterior por el impulso del deseo humano de gestionar lo cercano, su convivencia, identidad y bienestar. De ahí la importancia de considerar que los territorios, más que espacios geo-espaciales, constituyen espacios de la identidad, anclados en gran medida en la historia y cultura comunes que dan lugar a sentidos de pertenencia, identificación y diferencia. En la perspectiva del autor citado, tanto la identidad como el territorio han de reconocerse como temas centrales del presente, ya que permiten identificar la mirada de una comunidad sobre sí misma y sobre las demás, así como los valores en los que se reconoce y los niveles de confianza para enfrentar futuros de riesgo.

Zallo (2002) también plantea que en los tiempos actuales resulta difícil el papel de los territorios y las políticas regionales, dado que en la globalización los ámbitos global, estatal y metropolitano tienen mayor peso en el mundo. Esto en virtud que en la forma actual de mundialización económica y comunicativa no se da prioridad a las regiones interiores de los Estados.

En la perspectiva de Teresa Llorens Carbonell (2009), tanto los procesos migratorios como el incremento de la diversidad constituyen algunos de los principales factores del cambio social actual en el contexto de la globalización, que tienen su principal expresión en las localidades municipales. El prisma desde el cual se analiza la relación global-local, coloca a las políticas públicas como centro neurálgico para la toma de decisiones que favorezcan la integración y convivencia ciudadanas, todo para garantizar el respeto a los derechos y deberes, la igualdad de oportunidades y el acceso a los servicios y recursos sociales. Llorens Carbonell indica que estos factores tienen un origen global pero consecuencias locales, como pueden ser "la percepción de la pérdida de la identidad simbólica del barrio por la llegada de nueva población o la distinta concepción que unos y otros tenemos del uso del espacio público, de la calle y las plazas" (Llorens, 20).

Aunque el referente de esta autora es la sociedad española del Siglo XXI, podemos encontrar algunos paralelismos con las realidades Latinoamericanas, sopesadas las diferencias económicas, socioculturales y políticas. En México, por ejemplo, tanto el aumento significativo de las migraciones hacia los Estados Unidos de Norteamérica, como los flujos migratorios internos, constituyen una de tantas evidencias de los efectos de la globalización. No obstante es importante no desestimar que también suponen fenómenos vinculados a condiciones específicas, como la desigualdad y la pobreza que enfrentan amplios grupos de la población.

Esta condición particular (la de la pobreza), ha estado presente en la agenda política mexicana y se han diseñado distintas estrategias de política pública para atenuarla, específicamente a partir de 1982, cuando el gobierno mexicano las reorientó a los grupos más vulnerables, sobre la base de un criterio selectivo. No obstante los distintos programas y acciones realizados con tal propósito, sólo muy parcialmente, han logrado sus objetivos. Lo cual es evidente cuando Organismos como la CONEVAL (Consejo Nacional de Evaluación de la Política de Desarrollo Social) ha reportado que la población en condición de pobreza en el país aumentó de $44.5 \%$ a $46.2 \%$, lo que corresponde a un incremento de 48.8 millones de personas en situación de pobreza a 52.0 millones entre 2008 y $2010^{1}$.

A nuestro parecer un elemento de nodal importancia, entre muchos otros, que influyen en el fracaso (o logro parcial) de las políticas de combate a la pobreza, tiene que ver con la homogeneidad de las mismas. Es decir son políticas aplicadas sin considerar las diferencias y particularidades (y diversidad) de los entornos 
locales en los que se ponen en práctica. Pensemos, por ejemplo, en los entornos espaciales donde habitan personas y familias procedentes de diversas zonas del país, con distintas cosmovisiones, ancladas en prácticas y significados de orden étnico, religioso, político, etcétera. $\mathrm{O}$ pensemos en las asincronías existentes entre "la dimensión cultural, el imaginario sobre la familia de instituciones y personas, y las estructuras y funcionamientos de las familias reales" (Arriagada, I.16), las cuales se han diversificado en los últimos años, tanto en su composición como en su funcionalidad ${ }^{2}$. El componente identitario y simbólico, en estas nuevas realidades y contextos (lo que se considera más o menos importante por parte de los destinatarios de los distintos programas, las posibilidades y capacidades para "aplicar" en los requerimientos institucionales y así ser sujeto de determinados beneficios) está fuertemente implicado, tanto en la valoración como en las posibilidades de apropiación de los recursos de las políticas públicas.

Nuestro interés, en el presente trabajo, tiene que ver con la diversidad y heterogeneidad de los contextos de segregación urbana, a los que están dirigidos gran parte de los programas de combate a la pobreza. En particular, nos interesa reflexionar sobre algunas de las implicaciones prácticas y simbólicas de dicha diversidad, encontradas en dos barrios de la periferia de Hermosillo.

\section{Cuando la noción de "comunidad" se desdibuja}

La idea que un determinado entorno socioespacial urbano (barrio) constituye un conjunto de personas, con características comunes, que habitan en un espacio común, es una afirmación que no puede sostenerse cuando nos adentramos en las representaciones sociales y esquemas simbólicos de sus pobladores.

En una investigación que realizamos en dos barrios precarios de la periferia de la ciudad de Hermosillo, encontramos que la diversidad (y el conflicto) constituye su característica más relevante. Si bien la cohabitación espacial está presente (en un espacio físico de límites precisos), de acuerdo con los sentidos-valoración que sus habitantes imprimen al lugar, pareciera que el mismo entorno se superpone en múltiples espacios identitarios a partir de diversas significaciones.

A partir de los testimonios de nuestros entrevistados fue posible advertir el contraste en las formas de percibir el entorno inmediato y de valorar, tanto las prácticas propias como las de los demás, lo que se traduce en batallas simbólicas que afloran a través de las narrativas de los entrevistados alrededor de una amplia diversidad de aspectos: el entorno inmediato (sentidos del lugar), las prácticas y los estilos de vida.

Cabe aclarar que la movilidad espacial constituye la característica central de las trayectorias sociales de nuestros entrevistados. Es decir, se trata de sujetos itinerantes que se han visto obligados a trasladarse (en más de una ocasión) de un punto a otro de la geografía nacional o estatal para lograr mejores condiciones de vida. En esta búsqueda muchos de ellos han cifrado sus esperanzas en el cruce de la frontera norte. Otros por motivos diversos se han detenido (temporal o definitivamente) en la capital del estado de Sonora y se han asentado en barrios de la periferia de Hermosillo ${ }^{4}$.

\section{La diversidad simbólica}

Una característica importante encontrada en las representaciones del lugar, entre nuestros sujetos de estudio, es que éstas se enmarcan en una dimensión tridimensional, o en lo que se ha denominado la 'trialéctica', donde lo físico, lo social y lo imaginario se fusionan (Soja, citado por Oliva y Camarero,70). Así, encontramos referentes diversos que aluden, tanto al espacio físico como al espacio social. Esta multireferencialidad confirma la estrecha relación entre las dimensiones física, social y simbólica en los sentidos del lugar y las identidades; asunto ampliamente tratado en las ciencias sociales. ${ }^{5}$. Como afirma Bourdieu, los agentes sociales se constituyen como tales en y por la relación con un espacio social y con las cosas, en tanto se apropian de ellas y las asumen como propiedades y como referentes simbólicos (Bourdieu, 119-120).

A continuación, presentamos algunos de los referentes a partir de los que nuestros entrevistados establecen criterios de diferenciación, cuando valoran el entorno socioespacial del barrio.

\subsection{El referente región}

En el escenario explorado encontramos que los agentes se distinguen de acuerdo al referente región, que constituye un potente criterio organizador de las identidades en México ${ }^{6}$. Como puede apreciarse en la figura que más adelante presentamos, éste escenario adquiere especial relevancia en tanto que se encuentra presente en las dos generaciones y en ambos géneros, 
al igual que el espacio inmediato (lugar de residencia actual) y las prácticas religiosas.

Cuando la distinción se establece a partir de este referente, la distancia social que a partir de él se fija es directamente proporcional a la distancia física. Esto es que la distancia simbólica es mayor cuanto más alejado de Sonora se encuentra el lugar -la región- de la que proviene o con la que se relaciona al Otro. Vinculados expresamente a la región, la diferencia se establece a través de atributos físicos (la estatura, la vestimenta), sociales (las costumbres, el tipo de trabajo, el estatus económico) e incluso étnicos (los indígenas). Pero además son utilizados de forma tal que con ellos se fijan también jerarquías (los norteños son "altos y fuertes", "menos pobres", "más trabajadores", "más francos", "tienen la misma sangre").

Las diferencias simbólicas se erigen sobre la base de un criterio organizador que incluye y excluye, en función de la proximidad o distancia en el espacio físico. Así, éstas expresan más semejanzas con los más cercanos en el espacio regional, y mayor distancia con los más lejanos. Ejemplos: "Es gente de allá del sur, hasta en el tamaño es otro tipo de gente, o sea físicamente", Varón mayor, barrio 1. "Ya ves como son los guachos de allá [Distrito Federal] que quieren todo el mundo para ellos solos", Mujer mayor, barrio 1. "La gente de Sinaloa, Chihuahua y Sonora pues se parecen, tienen el mismo estilo, tamaño, es la misma altura", Varón joven, barrio 1 .

Figura 1: Fuentes de significado para la diferenciación

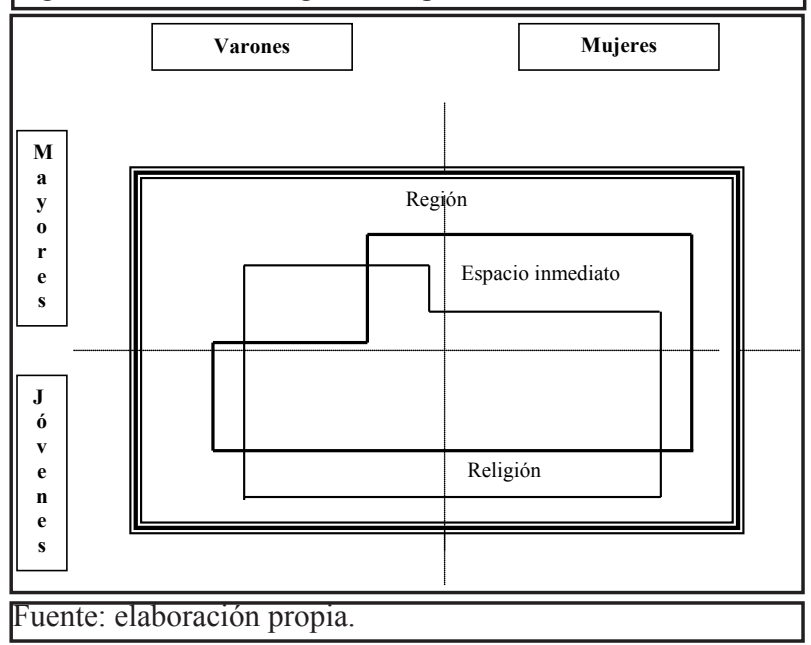

Esta misma relación se observa si la condición étnica está implicada, además de la región. "Los mixtecos tienen otro tipo de convivir, tienen otras costumbres, no hacen amistado con uno, nosotros los tenemos señalados como el sector ponderosa o el sector Oaxaca", mujer joven, barrio 2; “...a las indígenas de la Combate la gente las hace menos, dicen que son cochinas y que la comida que hacen les da asco", mujer joven, barrio 1 .

En estos procesos de similitud y diferencia, siguiendo a Jenkins (1996), diremos que la identidad nominal asociada a la región (los del norte, los del sur, los de los pueblos, los indígenas) se encuentra relacionada con un amplio rango de virtualidades; esto es la diferencia entre el nombre de la etiqueta y lo que significa portarla. En virtud de ello, el Otro desde la perspectiva de los agentes locales (los norteños), asumido como el nosotros en el polo contrario (entre los del sur) revela significados distintos en tanto que dimensión virtual de la identificación (lo que significa portar la etiqueta):

La práctica y la experiencia de la pertenencia a una comunidad, vis a vis, con otros miembros y foráneos es la dimensión virtual de la identificación: puede ser, en un alto grado, individual o idiosincrática (...) cada una es una dialéctica de identificación grupal y categorización grupal. Cada una retroalimenta a la otra (Jenkins, 24).

Por ello es que los más distantes (con quienes simbólicamente se reconocen más diferencias que semejanzas) se autoperciben de una forma que contradice los significados asignados cuando quien los ha fijado se convierte a su vez en el Otro. "Nosotros, las personas que venimos de allá [sur del país] trabajamos las 24 horas, somos responsables", varón mayor no fundador, barrio 1; "Nosotros somos un grupo de indígenas; aquí son yaquis, nosotros somos mixtecos. Si no nos quieren ayudar no hay problema, nosotros seguimos trabajando y nos ayudamos nosotros mismos", varón joven, fundador, barrio 2 .

Por otro lado, puede apreciarse también que los norteños, a diferencia de los sureños, utilizan una diversidad de referentes (el físico, la condición económica, el trabajo, las costumbres) para establecer distancias simbólicas; es decir que éstas son mayores si las fijan los primeros que si lo hacen los segundos (cuyos referentes son la cultura y la condición étnica), quienes, además de encontrar afinidades con el Otro generalizado, los excluye para distinguirse de ellos. 


\section{2. Los referentes del entorno inmediato}

Además del criterio de distinción arriba mencionado, encontramos otros no menos importantes a través de los cuales se expresa la diversidad simbólica (el trabajo, los ingresos económicos, los estilos de vida, los usos del espacio, las prácticas religiosas y políticas). Estos se utilizan para establecer diferencia o afinidad con el Otro próximo en el espacio inmediato (el barrio).

También encontramos diferencias generacionales y de género importantes. En el caso de las primeras: estas se aprecian sobre todo en lo que respecta al capital social, económico o político. Así, para distinguirse los sujetos mayores son más proclives a valorar las relaciones sociales, añorando formas de interacción basadas en las prácticas solidarias: "íbamos a visitar a las personas más necesitadas; mira, te traemos esto de gusto, de mucho corazón; nomás por satisfacción a la humanidad y aquí nada de eso; si les pides un tomate ¡uy!, que no tienes para pagar", mujer mayor, barrio 2: "no participa la gente pa' meter el agua, decían que no les corresponde esa calle, no les importan los demás", varón mayor, barrio 1 .

Por su parte, los jóvenes valoran las diferencias en el capital económico poseído o en las prácticas políticas: "en cuestiones de alimentación, de ropa o de beneficios estoy rico en comparación con ellos", varón joven, barrio 1; "cada persona opina diferente por lo mismo, porque hay diferentes partidos, muchos líderes, aquí abajo hay una, aquí arriba hay otra”, varón joven, barrio 1 .

Las mujeres tienden a distinguirse (tanto ellas mismas como a través de la mirada masculina) como trabajadoras y más participativas en las obras de mejoramiento colectivo. No así los varones quienes, si bien se autodefinen a partir del trabajo, son vistos por las mujeres como poco responsables: "nosotras, las mujeres, abrimos la zanja, pues no había hombres; mientras los hombres trabajaban nosotras acá", mujer mayor, barrio 1 ; “...los hombres andan más en la parranda, las mujeres participan más aquí en la colonia”, varón joven, barrio 2; "hay muchas mujeres que no pueden trabajar porque tienen un montón de niños, mujeres abandonadas que no las ayuda el hombre", mujer mayor, barrio 1 .

Las prácticas constituyen también referentes para establecer fronteras en el entorno inmediato. La diversidad simbólica hace que quienes se encuentran relativamente próximos en el espacio físico se perciban socialmente distantes en función de la forma en que son valorados los estilos de vida o las prácticas religiosas y políticas: "ellos le dedican muy poco tiempo a la familia, se salen del trabajo y se dedican a pistear [beber]", varón joven, barrio 1; "yo veo que las mamás se van y dejan a los hijos solos, como que ellas ya están impuestas [acostumbradas] y yo no", mujer joven, barrio 1; "somos gente más católicos y aquí les habla uno de las cosas de Dios y lo ignoran a uno", varón mayor, barrio 2 .

Pero también la ubicación en el espacio físico ${ }^{7}$ constituye un referente en la diversidad simbólica que hemos señalado hasta ahora, con lo que puede decirse que las diferencias se establecen en función de la posición en él, las cuales se encuentran relacionadas con el mayor o menor acceso a determinados bienes y servicios. Así, los que viven en la parte baja del barrio 1 , son reconocidos como los mejor situados en el espacio social (en función de las distintas formas del capital poseído) y los situados en la parte alta de los cerros son considerados como los peor situados: "aquí vives con gente de tu capacidad, de tu categoría, la gente que te puede entender como lo que eres, como una persona humilde“, varón joven, parte alta del cerro, barrio 1; "esas personas tienen unas buenas casas aquí abajo", mujer mayor, parte baja, barrio 1; "los de arriba se conforman porque están más amolados, hay muchas casas de cartón, es gente muy pobre", varón joven, parte baja, barrio 1 .

Por su parte, quienes viven en el barrio 2 se distinguen espacialmente, con aquellos con los que más distancia social establecen, es decir con un grupo de vecinos que son indígenas mixtecos: "los mixtecos están allá, en las orillas; como ellos están acostumbrados a diferentes formas, tienen otras costumbres, es rara la mujer que te contesta pero entre ellos sí, ellos son muy unidos", mujer joven, barrio 2. Como puede apreciarse se trata de percepciones múltiples a través de las que se expresa la diversidad simbólica, sedimentada en formas de de percepción y apreciación, ancladas a diferentes trayectorias y posiciones en el espacio social, donde se engendran los habitus (que orientan tales categorías de percepción), en virtud de su capacidad para operar como "principios generadores de prácticas distintas y distintivas" (Bourdieu, 18).

\section{3. Fronteras simbólicas y campos conflictuales}

El contraste en las formas de percibir el entorno inmediato y de valorar tanto las prácticas propias como las de los demás, a partir de la posición que se ocupa 


\section{霖 Sonta}

en el espacio social (y físico), se traduce también en batallas simbólicas que pueden ser captadas a través de las valoraciones, con las que se sancionan o critican comportamientos, con las que se valoran actitudes o estilos de vida, etcétera. Estas batallas afloran a través de las narrativas de los entrevistados alrededor de una amplia diversidad de aspectos: el entorno inmediato (el lugar), las prácticas y estilos de vida y las formas de liderazgo (religioso, político) que en él se asumen.

Figura 2: Diferenciación y ámbitos de conflicto

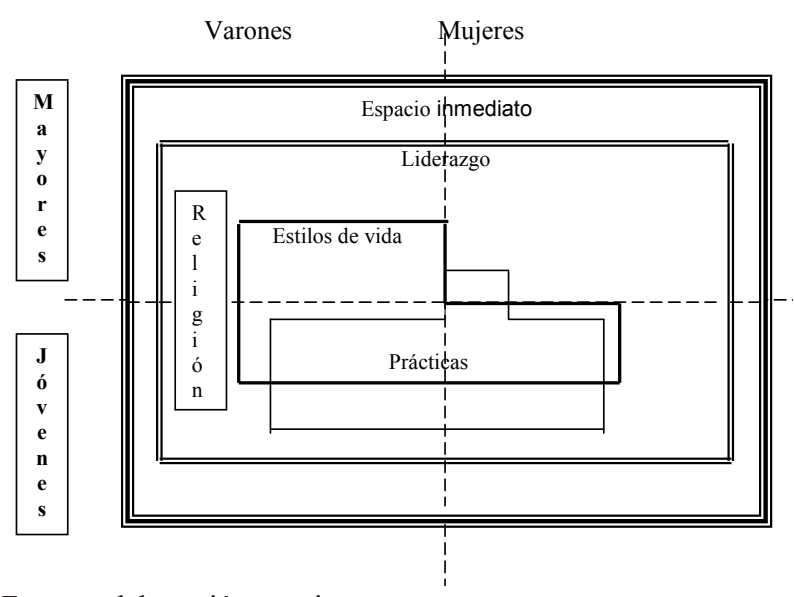

Fuente: elaboración propia.

El comportamiento del Otro es sancionado, ya sea si se trata del uso de los espacios comunes: "nosotros hemos alegado por qué los vecinos tiran el agua en la calle", varón mayor, barrio 1 , como si se trata de las prácticas y los estilos de vida: "se ponían a pistear [beber] y la música a todo volumen hasta que tuvimos una discusión muy fuerte, ya casi andábamos llegando a los golpes", varón joven, barrio 1; "he visto que algunas mamás dejan a sus niños con otras personas o he visto que les gritan, que los tratan mal y pues no está bien", mujer joven, barrio 2 .

Pero igualmente, las luchas simbólicas se expresan cuando se valoran las prácticas religiosas. La diversidad de $\operatorname{credos}^{8}$ desata percepciones encontradas que oponen y distancian a los agentes sociales en medio de la competencia por el capital simbólico: "aquí está otra iglesia evangelista que nos quitaba muchos seguidores, pues cada quien va buscando su verdad y respeto la decisión de cada quien", varón mayor, barrio 1; "aquí, cuando predicamos, la gente dice que sería bueno cambiar pero no cambian porque ser bueno es ser tonto", mujer joven, barrio 1;"'todo el tiempo hay una mafia en la iglesia de señoras que ayudan al padre, pero esa no es la realidad, la realidad es otra, o sea que le cierra la puerta a los niños", varón joven, barrio1.

Otro espacio de conflicto es aquel que tiene que ver con el liderazgo (que ejercen figuras como el sacerdote, el pastor o el líder del barrio), en torno al cual se desencadenan enfrentamientos en función de los diferentes conceptos éticos desde los que éste se valora. Dichas batallas simbólicas revisten especial importancia dado que las narrativas se encuentran pobladas de ellas.

De acuerdo a lo expresado (y quien lo expresa), existe un acuerdo generalizado (ambos géneros, ambas generaciones) de descrédito hacia los líderes barriales, lo que supone la permanencia de prácticas clientelares que contribuyen a que se mantenga este tipo e valoración. Asimismo el sentido generalizado de descrédito hace que los efectos de la diversidad de credos sean percibidos como incapacidad de los líderes religiosos para atraer seguidores o el cambio de religión como elección fincada en el interés personal para obtener dividendos.

\section{Conclusiones}

La realidad explorada ofrece imágenes múltiples, en cuya compleja configuración se amalgaman tiempo, espacio, estructura y cursos de acción. Así, tenemos que el panorama que hemos mostrado aparece como un mosaico de múltiples identidades, atendiendo a las particularidades de las similitudes y diferencias, que constituyen los principios de la identidad y el corazón de la vida social, simbólicamente construida por los agentes sociales (Jenkins, 19).

Si la identidad social constituye una realización práctica, un proceso; y si tanto las identidades individuales como las sociales se construyen en el juego dialéctico de procesos de definición interna y externa ${ }^{9}$, en el escenario explorado la construcción (o reconstrucción) identitaria supone un proceso inestable y confuso. Ello en virtud de que la diversidad de grupos (provenientes de diferentes regiones, con diferentes trayectorias y habitus, que además se encuentran situados en diferentes puntos del espacio físico y social), conlleva la existencia de 'espejos' distintos a través de los cuales la auto-imagen ofrecida individualmente es devuelta de diferentes formas, en virtud de las distintas perspectivas simbólicas desde las cuales esta es valorada por los demás, situación que no dista mucho de la condición que se experimenta cuando se cruzan las fronteras entre un país y otro. 
De tal manera, lo que se piensa que se es (lo que se cree ser), puede ser percibido de múltiples formas (incluso contradictorias), las cuales influyen en el tipo y curso de las interacciones. Lo anterior coincide con la aserción hecha por Jenkins (1996, 20-22), en el sentido que los agentes sociales reflexivamente incorporan la imagen devuelta por los demás a su identidad personal (o no), lo que puede modificar la manera que estos se muestran a los otros.

Por otro lado, si bien la identidad social construida en torno al símbolo común de región marca un relativo sentido de pertenencia compartido, en la práctica de la identificación este asume significados diversos (más de diferencia que de semejanza, como ya ha sido mostrado), lo que refuerza la hipótesis de la inestabilidad y/o confusión atinentes a los procesos de identificación social. Lo mismo ocurre si atendemos a estos procesos de acuerdo al referente entorno inmediato, configurado por elementos de orden físico (los de arriba, los de abajo) y por las diferencias percibidas en las prácticas y los estilos de vida que, además de ser referentes para establecer diferencias, constituyen fuentes de colisión y enfrentamiento, es decir campos conflictuales.

No obstante que los elementos anteriores constituyen efectos de la diversidad de posiciones, prácticas, estilos

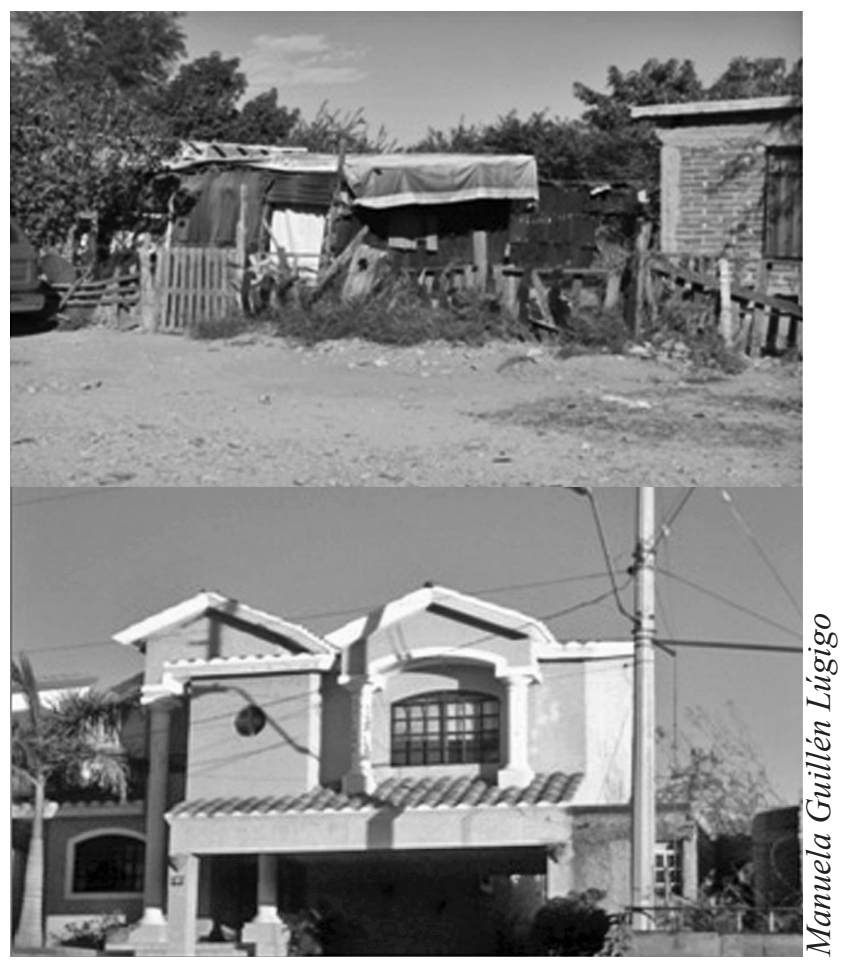

de vida y cosmovisiones, el conjunto de evidencias encontradas nos lleva a afianzar la aserción del papel crucial que juega la diversidad simbólica en los procesos de identificación/diferenciación en las configuraciones identitarias de quienes "comparten" un determinado territorio. Pero también nos lleva a plantear la hipótesis que la diversidad simbólica tiene implicaciones en las formas (y volumen) de apropiación de los bienes y servicios emanados de las políticas públicas de combate a la pobreza.

La realidad de las múltiples diversidades que hemos logrado identificar no sólo implican construir y reconstruir saberes y competencias, sino un proceso de (re) construcción identitaria, es decir de continuas redefiniciones entre la condición anterior y la actual, de (re) categorizaciones entre lo que se pensaba que se era y lo que se piensa que se es; todo esto mediado por las imágenes que devuelven los demás espejos (los otros). Asimismo pueden verse como procesos de hibridación (García Canclini, 1990) en los que las prácticas que existían en forma separada se combinan para generar otras nuevas, igual que lo hacen los contextos en que estas se inscriben.

Esta realidad, plagada de diferencias, no debe ser soslayada por las políticas de combate a la pobreza. Las políticas y programas hacia los entornos locales cuyos grupos tienen intereses heterogéneos, formas distintas de vivir y de apreciar la condición propia y la de los demás, han de adaptarse a las particularidades de estos entornos, ya que dirigirlas a la denominada "población objetivo" en lo general, supone que éstas beneficien más a unos grupos que a otros, debido a la distribución desigual de distintas formas de capital: económico, cultural, político y simbólico.

\section{Notas}

1 Véase el documento Pobreza 2010. Porcentaje de la población en pobreza según entidad federativa, 2010. En http://www.coneval.gob.mx/cmsconeval/rw/pages/ medicion/index.es.do

2 De acuerdo con el estudio realizado por Irma Arriagada $(2007,10)$ se encontró que entre 1990 y 2005 , las familias urbanas en México se han diversificado. El modelo biparental con hijos se redujo de 46.3 por ciento en 1990 a 41.1 por ciento en 2005. La investigadora refiere que este modelo coexiste con la familia extendida de tres generaciones $(21.7 \%)$. El $12.2 \%$ de las familias son nucleares monoparentales (principalmente a cargo de mujeres) y el $9.7 \%$ corresponde a hogares unipersonales. 
Refiere, además, que existe gran variedad de arreglos familiares: personas que viven solas, parejas sin hijos, en hogares monoparentales, en uniones consensuales o en uniones homoparentales. Asimismo, refiere haber encontrado un creciente número de familias recompuestas (parejas que se unen y llevan consigo a sus hijos de uniones anteriores y de otros padres) y familias a distancia (producto de las migraciones de alguno de sus integrantes). Los cambios son importantes en la percepción de quienes son integrantes de esas familias, la mayor individuación de sus miembros y la aceptación de diversos lazos familiares y lógicas afectivas al interior de su estructura.

3 El objetivo de la investigación que aquí damos cuenta, fue indagar la relación entre las reconfiguraciones productivas ocurridas en la región, como parte del proceso de vinculación de Sonora con los mercados globales, el crecimiento de la ciudad de Hermosillo (una de cuyas expresiones ha sido la expansión de las zonas periféricas segregadas) y las identidades de los grupos en condiciones de pobreza.

4 El escenario empírico de nuestra investigación está constituido por dos barrios precarios, situados en la periferia de la ciudad de Hermosillo, ambos producto de un proceso de invasión. El primero surge a mediados de los años sesenta (que denominaremos barrio 1) y el segundo a finales de los años noventa del Siglo XX (que denominaremos barrio 2). Muchas de las familias afincadas en ellos provienen de diversas zonas rurales del estado de Sonora, de diferentes estados norteños (Sinaloa, Chihuahua, Baja California Norte) y de algunos estados del sur del país (Jalisco, Oaxaca y Veracruz).

5 La relación entre el espacio físico habitado y las connotaciones sociales y simbólicas asociadas a él ha sido tratada en diferentes campos disciplinarios como la Psicología (Milgram, 1984; Proshansky et al, 1983, Lalli, 1988), la geografía humanista (Tuan, 1980; Relph, 1976; Buttimer, 1980), la Sociología (Lefebvre, 1986; Soja, 1996; Park, 1925; Bourdieu, 1999; 2000; Oliva y Camarero, 2002), por mencionar algunos.

6 Esto coincide con los resultados de la investigación realizada por Pablo Vila -en la frontera entre Ciudad Juárez (México) y El Paso (Texas)- a partir de los cuales se afirma que los mexicanos en general utilizan un sistema clasificatorio basado en el criterio organizador de región para entender comportamientos y actitudes, con lo que este sistema regionalista les permite anclar un rótulo identitario en un área geográfica específica. http://www.firewall.unesco.org/issj/ rics159/vilaspa.html, extraído el 20 de diciembre de 2004.

7 En uno de los asentamientos explorados (barrio 1), la topografía es irregular. La parte más cercana a la carretera, reconocida por los vecinos como "la parte de abajo", es llana (aunque pedregosa y accidentada) y está dotada de la infraestructura urbana básica (asfalto en algunas de las calles, agua potable, luz eléctrica y alcantarillado) y la mayoría de las viviendas son de ladrillo. Existen, asimismo, un conjunto de pequeños cerros que operan como límite natural con zonas residenciales aledañas, que fueron poblándose paulatinamente con posterioridad al proceso de invasión que dio lugar al barrio. En esta parte, reconocida como "la parte de arriba" muchas de las viviendas carecen de servicios, especialmente drenaje y pavimentación, y las viviendas están construidas con cartón, lámina, madera y materiales de desecho.

8 Algunos de nuestros sujetos de estudio, en los dos barrios explorados, revelaron la existencia de múltiples credos y centros de culto religioso.

9 Richard Jenkins afirma que el self (al mismo tiempo individual e intrínsecamente social) surge de la interacción y que las identidades individuales y colectivas son construidas sobre la dialéctica de la identificación interna-externa. El proceso opera de la siguiente manera: el individuo se presenta a otros en una forma particular. Cuando esta presentación es aceptada (o no), se convierte en parte de su identidad ante los ojos de los otros (o no). Las respuestas de los otros a su presentación lo retroalimentan. Así, la presentación constituye el momento interno de la identificación y la forma en que esta es recibida, valorada, aceptada o rechazada, el momento externo. Es decir que si bien lo que la gente piensa sobre los demás no es menos importante que lo que estos piensan sobre sí mismos, esto no es suficiente para afirmar una identidad. Esta tiene que ser validada (o no) por aquellos con quienes se interactúa (Jenkins, 20-22).

\section{Bibliografía}

Arriagada, I. (2007). Familias latinoamericanas: cambiantes, diversas y desiguales. Papeles de Población, No.053, pp. 9-22. Recuperado de http://redalyc.uaemex.mx .

Augé, M. (1992). Los "no lugares". Espacios del anonimato. Una antropología de la sobremodernidad. Barcelona: Gedisa.

Bourdieu, P. (2000). La Distinción. Criterio y bases sociales del gusto. Madrid: Taurus. (1999). Razones Prácticas. Sobre la Teoría de la Acción. Madrid: Anagrama (Colección Argumentos).

Buttimer, A. y Seamon, D. (Eds) (1980). The Human Experience of Space and Place. London: Croom Helm.

Carrasco, R. (1999). Enfoque conservador. Política social sin cambios de fondo. Etcéter@. Política y Cultura en Línea. Recuperado de http://www. etcetera.com.mx/2000/390/car390.html . 
CONEVAL (2010). Porcentaje de la población en pobreza según entidad federativa 2010. Recuperado de http://www.coneval.gob.mx/cmsconeval/rw/ pages/medicion/index.es.do.

Burhan, G. (1999). Globalización, deculturación y crisis de identidad, CIDOB (Afers Internacionals), No. 44, Barcelona.

García Canclini, N. (1990). Culturas Híbridas. Estrategias para entrar y salir de la modernidad. México: CNCA-Grijalbo.

Grossberg, L. (1996). "Identity and Cultural Studies Is That All There Is?", en Questions of Cultural Identity (Stuart Hall \& Paul du Gay, Ed.). London, Sage Publications, pp. 87-107.

Giddens, A. (2000). Un mundo desbocado. Los efectos de la globalización en nuestras vidas. Madrid, Taurus.

Jenkins, R. (1996). Social Identity. London, Routledge.

Lalli, M. (1988): Urban Identity. En D. Canter (Ed.) Enviromental social Psychology, NATO ASI Series, Behavioural and Social Sciences, Vol. 45, Dordrech, The Netherlands: Kluwer Academic Publishers, pp. 303-311.

Lefebvre, H. (1986): La production de l'espace, París: Anthropos.

Lewellen, T. (2002). The Anthropology of Globalization. Cultural Anthropology Enters the 21st Century. Westport: Bergin and Garvey.

Llorens, T. (2009) Innovación política para una nueva realidad social, Intervención Psicosocial, No. 1, Vol. 18, pp. 19-27. Disponible en versión electrónica, en http://redalyc.uaemex.mx/ .

Michael, M. (1996): Constructing identities. London, Sage Publications.

Milgram, S. (1984). Cities as Social Representations. En S. Moscovici, y R. Farr (eds). Social Representations. Cambridge: Cambridge University Press.

Oliva, J. y Camarero, L.A. (2002). Paisajes sociales y metáforas del lugar. Pamplona: Universidad Pública de Navarra.

Olivé, L. (1999). Multiculturalismo y pluralismo. México: Paidós.

Paredes, R. (2006). Políticas públicas, pobreza y equidad de género. Espacio Abierto, No. 4, Vol. 15, pp. 741-757.
Park, R., Burguess, E. \& Mackenzie, R. (1925). The City. Chicago: University of Chicago Press.

Pinxten, R. (1997). Identidad y conflicto: personalidad, socialidad y culturalidad. CIDOB (Afers Internacionals), No. 36, Barcelona.

Proshansky, H.M., Fabian, A.K. y Kaminoff, R. (1983). Place-Identity: physical world socialization of the self. Journal of Environmental Psychology, 3, 57-83.

Relph, E. (1976). Place and Placelessness. London: Pion.

Sandoval, S.A. (2003). Hibridación social: un modelo conceptual para el análisis de la región y el territorio. Región y Sociedad, vol. XV, n 28 , pp. $48-80$.

Soja, E. (1996). Thirdspace. Journeys to Los Angeles and Other Real-and-Imagined Places. Oxford: Blackwell.

Tajfel, H. (1982). Social Identity and Intergroup Relations. Cambridge: Cambridge University Press.

Téllez-Girón, R. (2002). Identidad sociocultural y globalización. Ciencia y Cultura, 45 (9): 19-24.

Tuan, Y.F. (1980). Rootedness versus Sense of Place. Landscape, 24, 3-8.

Valera, S. (1999). El significado social del espacio: estudio de la identidad social y los aspectos simbólicos del espacio urbano desde la psicología ambiental. Polis Research Center. Recuperado de http://www.ub.es/escult/valera/cap1.htm.

Vila, P. (1997). Construcción de identidades sociales en contextos transnacionales: el caso de la frontera entre México y los Estados Unidos. Recuperado de

http://www.firewall.unesco.org/issj/rics159/ vilaspa.html .

Zallo, R. (2000). Nuevas políticas para la diversidad: las culturas territoriales en riesgo por la globalización. Pensar Iberoamérica (Revista electrónica), http://www.oei.org.

(2002). Políticas culturales territoriales. En E. Bustamante (coord.) Comunicación y cultura en la era digital. Industrias, mercados y diversidad en España. Barcelona: Gedisa. 